\title{
EL MEGATILISMO EN LA PENÍNSULA IBÉRICA
}

\section{MEGALITHISM IN THE IBERIAN PENINSULA}

\author{
por \\ ANA M MuÑOZ AMILIBIA
}

RESUMEN El megalitismo de la Península Ibérica se inició en el Neolítico avanzado de cerámicas lisas del IV milenio BC. Tuvo una larga evolución tipológica y cultural durante el Calcolítico, hasta la Edad del Bronce a finales del III milenio BC. El arte megalítico comparte sus raíces neolíticas, dentro de su evolución cultural y diversidad geográfica.

\begin{abstract}
The Iberian megalithic tombs started in the advanced neolithic of undecorated potteries of the IV millenium BC. It took a hugh tipologycal and cultural evolution during the Calcolithic, since the Bronce Age in the end of III milennium BC. The megalithic art shares its neolithic roots, in its cultural and geographic diversity evolution.
\end{abstract}

Palabras claves

Key words

\section{Megalitismo. Península Ibérica}

Megaliths. The Iberian Peninsula.

Quiero participar, aunque sea modestamente, en este homenaje de la Universidad de Sevilla a mi buen amigo y compañero Manolo Pellicer recordando su importante contribución al mejor conocimiento del Neolítico español. No puedo aportar grandes novedades o resultados de investigaciones recientes, como él merecería, sino más bien unas reflexiones sobre un aspecto de nuestro Neolítico peninsular en su etapa de madurez, que en otros tiempos incluíamos en el Calcolítico y que actualmente presenta una problemática que no es nueva, pero que se ha enriquecido con el resultado de las investigaciones de las últimas décadas, ya que el megalitismo sigue siendo unos de los campos de investigación mas atrayentes para los jóvenes prehistoriadores que trabajan en la Península.

El tema del megalitismo ha sido motivo de largas disertaciones y problemas para los prehistoriadores desde siempre. No en balde los grandes monumentos megalíticos construidos en piedra en Bretaña, Irlanda, Gran Bretaña o la Península Ibérica, representan la primera arquitectura monumental en el occidente de Europa, desde finales del V milenio BC. Su gran número y variada tipología, su aparente aparición ex novo, su prolongada utilización, y, sobre todo, el gran cambio social y religioso-funerario de que son reflejo, 
son suficientes argumentos para desarrollar una atractiva trama, en la que la Península Ibérica tiene un papel destacado.

Glyn Daniel, uno de los grandes especialistas en megalitismo en los años sesenta y setenta, comentaba que en una ocasión Gordon Childe le había dicho: "Si Vd. puede explicar satisfactoriamente el origen de los megalitos ibéricos, tiene la llave de todos los problemas megalíticos". Es posible que este fuera uno de los motivos por los que Daniel hiciera frecuentes viajes por España y Portugal y que pudiéramos oírle contar con cierta frecuencia los problemas del megalitismo en las charlas que impartía en la Universidad de Barcelona. Y, una vez más, sirve para recordar las reflexiones de Childe sobre la interpretación de tantos problemas de la Prehistoria europea y la originalidad y novedad de sus planteamientos, que tanto nos impresionaban a todos, y ,sin duda, su contribución a despertar el interés de los arqueólogos británicos por nuestra prehistoria, del que es buena muestra la excelente síntesis de Savory en 1968.

Hace ya casi treinta años que Renfrew -basándose en las dataciones de C 14 de monumentos megalíticos en Bretaña, Islas Británicas, Dinamarca y Malta-propuso que el megalitismo de Europa occidental se había iniciado antes que en ningún otro lugar del mundo, y que las cámaras abovedadas de piedra podían remontarse al IV milenio a.C. en fechas no calibradas (Renfrew 1973). Pero, sobre todo, se relacionó el comienzo del megalitismo con la expansión de las nuevas formas de vida neolítica. Así, las manifestaciones megalíticas nos acercaban a un aspecto del mundo social y religioso de las poblaciones prehistóricas de la época, siendo testimonio del profundo proceso de cambio experimentado. El megalitismo es sin duda una parte muy importante del Neolítico pleno de Europa occidental -el neolítico de cerámicas lisas de Piggott-, sobre todo atlántica y continental. En la actualidad, una vez rechazadas las teorías difusionistas del origen mediterráneo oriental del megalitismo europeo, parece que todo el mundo admite su origen local o por lo menos occidental, aunque, una vez pasado cierto radicalismo indigenista, se valoren las interrelaciones atlánticas o mediterráneas mas o menos próximas.

Aunque no contaba con dataciones absolutas, Pedro Bosch Gimpera en los años treinta ya defendía que en Portugal existió un foco de "creación" y "evolución" de las construcciones megalíticas, que consideraba independiente y mas antiguo que el posterior desarrollo del megalitismo peninsular. Bien sea porque escribía en español o porque la influencia de las ideas orientalistas de Siret habían tomado carta de naturaleza, el hecho es que durante mucho tiempo, no se concedió mayor antigüedad al megalitismo occidental, a pesar de que ya Cartailhac, Nils Aberg y el mismo Bosch Gimpera admitían una evolución del megalitismo desde los tipos simples a los complejos, lo mismo que O. Montelius en su clasificación de las tumbas megalíticas del norte de Europa. En 1965, en un interesante artículo sobre la cronología del arte rupestre seminaturalista y esquemático, al tratar de la diferenciación cultural del Neolítico de las regiones peninsulares, se refería a la continuidad en Portugal de las tradiciones mesolíticas tipo Muge en las sepulturas megalíticas, en las que "los primeros periodos son evidentemente neolíticos", (Bosch-Gimpera 1965: 5). Así volvía sobre la antigüedad y el carácter neolítico del megalitismo portugués, antes de que Renfrew expusiera sus tesis en base a las dataciones de C 14 .

En otro lugar, me ocupé brevemente de las distintas explicaciones que se han ido dando sobre el origen del megalitismo local : incremento de población, reafirmación de los derechos de explotación de un territorio por parte de sociedades segmentarias, fuerte cohesión social de un grupo capaz de emprender tales construcciones, etc. (Muñoz 1996). Son varios los autores que coinciden en valorar la construcción del monumento megalítico como una reafirmación territorial. En este sentido, parece claro que no se trata simplemente del concepto de necrópolis - ciudad de los muertos- tan propio del neolítico avanzado centroeuropeo, y quizás de nuestros "sepulcros de fosa", dado que los megalitos aparecen tanto aislados como formando extensas necrópolis y también en lugares dominantes, que destacan en el conjunto de un paisaje y lejos de un lugar de habitación. Como en otras ocasiones, la explicación no es fácil ni puede resolverse sin considerar todos los factores que determinan el tiempo cultural en que se produce: substrato, asentamiento y su relación 
con el monumento, medio en el que se sitúa y análisis del motivo de la elección (económico, sacro), interrelación con lugares de habitación, de los megalitos entre sí y con otros tipos de enterramiento. En suma, intentar valorar el megalito en su contexto, significado y función precisa. Para ello, no hay duda de que hay que intentar llegar al pensamiento e ideología sobre todo a través de todos sus elementos: estructura, estudio del uso dado a cada microespacio, restos óseos y ritual del enterramiento, ofrendas de todo tipo, manifestaciones artísticas e ideología. Es fundamental también, tener en cuenta la larga perduración del megalitismo y su proceso final. Tratar de explicar el porqué un sistema funerario con fuerte carga ritual, puede servir a comunidades muy simples, de carácter fundamentalmente campesino y también a otras mas complejas, al parecer fuertemente centralizadas y jerarquizadas, según se han interpretado casos como el de Los Millares.

Ya no es válida la exclusiva interrelación entre megalitismo y sistemas de enterramiento múltiple, con poblados fortificados tipo Millares o Vilanova de San Pedro y los comienzos de la metalurgia que corresponden a una fase posterior del proceso, ya a finales del IV o comienzos del III milenio, que solemos llamar Calcolítico, cuando el megalitismo va evolucionando hacia formas estructurales muy variadas. En 1943, G. y Vera Leisner habían señalado que algunos megalitos del sur de Portugal y la provincia de Huelva, situados precisamente en zonas con recursos mineros de cobre, no mostraban ninguna relación con la actividad metalúrgica (Leisner y Leisner 1943). Incluso en el ajuar del Tholos de San Bartolomé de la Torre (Leisner y Pérez Núñez 1952) y en la necrópolis de Pozuelo, no se encontró metal, de lo que Cerdán y Leisner dedujeron sabiamente (no había dataciones de C14) que la necrópolis sería anterior al uso de la metalurgia (Cerdán, Leisner y Leisner 1952). La deducción de otros, en cambio, ha sido la de que en Huelva la metalurgia no comenzó hasta la edad del Bronce. En Portugal, aunque está bien documentada la metalurgia del cobre desde la primera mitad del III milenio, vemos que en el Alentejo, con numerosas minas de cobre (Sierra de Grándola, minas de Castro Verde), este es escasísimo en las tumbas megalíticas de Reguengos de Mosaraz (Leisner y Leisner 1951). En cambio, parece que empieza a usarse el cobre cuando las tumbas de falsa cúpula ya estaban en uso, a mediados del IV milenio a. C. TL, pero en escasa cantidad. En Estremadura el metal abunda mas, pero las sepulturas pueden ser mas tardías. A partir de los años sesenta, las primeras dataciones de C14 para el megalitismo portugués, parecían reafirmar su origen local (Leisner y Veiga 1963).

Sin embargo, desde finales de los años 60, los trabajos de Henrique Leonor Pina y José Pires Gonçalves en Monsaraz, con el descubrimiento de nuevos megalitos, de menhires grabados y arte rupestre, abrieron nuevas perspectivas y líneas de investigación que muestran una vez mas la riqueza y complejidad de el megalitismo portugués. Victor S. Gonçalves, que había estudiado a fondo el megalitismo y la metalurgia del Algarve oriental (Gonçalves 1989), reemprende la revisión y estudio de Reguengos de Monsaraz (Gonçalves 1999). En esta revisión pone de manifiesto la falta de base de las secuencias cronológicas de los monumentos establecidas a partir de su estructura y tamaño mas o menos simple e incluso de determinados objetos del ajuar. No cree que las cuevas artificiales o hipogeos de la región costera, hayan sido excavadas por los mismos constructores de antas que ofrendan en sus enterramientos las placas de esquisto con decoración geométrica. Las cuevas artificiales coincidirían con el inicio del Calcolítico, con sus cerámicas acanaladas y los primeros objetos votivos de caliza y quizás con la construcción de los primeros tholoi, de construcción menos costosa que las antas o megalitos, con uso frecuente de la pizarra en vez del granito y mas fáciles de utilizar sucesivamente, introduciendo el sepelio por el techo de la cámara, como en los hipogeos. Piensa que los enterramientos en cuevas naturales presentan el mismo ritual (enterramiento colectivo, deposiciones primarias, pero sobre todo secundarias y uso del ocre) que las antas e incluso las placas de esquisto grabadas. Serian las mismas poblaciones, que estacionalmente se trasladarían a la costa, las que aprovechaban la grutas naturales con fines funerarios en zonas donde era mas difícil construir monumentos por grupos de gran movilidad. La difusión del megalitismo se debería a un amplio movimiento de migración de ideas, de procesos y técnicas de construcción pero también de gentes. 
El mismo proceso se repetiría mas tarde con la construcción de poblados fortificados con torres huecas o macizas. Según Gonçalves el comienzo del Calcolítico en Portugal coincidiría con la segunda gran llegada efectiva de influencias mediterráneas. La primera oleada habría sido la del Neolítico antiguo (Zilhao 1992). Las antas, en cambio serian una creación atlántica, del noroeste atlántico, aunque es sumamente crítico con las dataciones de $\mathrm{C} 14$, tan problemáticas en sepulturas con enterramientos múltiples e incluso con muestras que pueden ser anteriores a la construcción del monumento y no relacionadas con él. En el caso de Reguengos de Monsaraz, solo hay tres dataciones seguras para el tholos Olival da Pega 2b (OP2b): 3303-2615, 2920-2505 y 2900-2501 B.C. (Gonçalves 1999: 31 y 116), aunque se puede establecer una cierta secuencia de la evolución de los monumentos -1 , pequeñas cistas; 2 , antas de corredor muy corto; 3 , antas de grandes dimensiones, generalmente con corredor largo o muy largo; 4 , tolhoi-, y calcular una duración de su uso a lo largo de dos milenios. Durante la segunda mitad del IV milenio se construyeron las dos grandes antas de corredor de Olival da Pega, que dieron ricos ajuares y fueron reutilizadas en el III, añadiéndole dos cámaras tipo tolos a la menor de ellas. (OP2) A partir de la primera mitad del III milenio en Reguengos de Monsaraz aparecen finas lajas verticales forrando el interior de las cámaras funerarias, y en los poblados murallas y torres. Esta secuencia de tres primeras fases de megalitos neolíticos, en Reguengos, coincide con las dos deducidas para el Alentejo por Zilhâo en base a las secuencias de la Gruta do Caldeirâo y la Gruta da Feteira: la primera de pequeñas antas de corredor corto, con ajuar de cerámicas lisas almagradas, microlitos y objetos de piedra pulimentada y la segunda, ya en el IV milenio, con la construcción de grandes antas como la de Comenda da Igrejia, con puntas de flecha, placas de pizarra y, en la Estremadura, utilización de cuevas sepulcrales naturales (Lapa do Fumo) y artificiales (Carenque 2) (ZILHÂO 1995). La continuidad de los trabajos y la riqueza de la zona arqueológica de Reguengos, entre el Guadiana y el Álamo, será sin duda fundamental para una mejor comprensión de una parte importante del megalitismo portugués, un auténtico paisaje ritual, por emplear un calificativo acuñado en los grandes complejos religioso-funerarios de Irlanda (Cooney 1990).

En el Sureste, el poblado de Los Millares y su necrópolis, y el inicio de la metalurgia, se desarrollaron casi medio siglo después que los primeros megalitos neolíticos occidentales dando un buen ejemplo de la larga vigencia de estas costumbres funerarias a lo largo del espacio peninsular. Es precisamente aquí, donde sería de gran interés el estudio del sustrato, de los asentamientos y enterramientos neolíticos de lo que Siret llamó "cultura de Almería". Aunque a través del Corpus del matrimonio Leisner se han hecho trabajos de gran interés que muestran estos antecedentes, faltan dataciones de C14 que permitan establecer secuencias (Acosta y Cruz Auñón 1981). Trabajos de prospección en necrópolis próximas a Los Millares, han revelado la existencia de comunidades megalíticas por lo menos independientes de la de Los Millares, como es el caso del conjunto megalítico de Alhama. En el "Pasillo de Tabernas", donde tenemos el importante asentamiento y necrópolis de Terrera Ventura con un sustrato claramente neolítico, las prospecciones parecen revelar estructuras de organización del megalitismo muy diversas a las del Valle del Andárax y también a las situadas en el valle del Almanzora, al otro lado de Los Filabres (Maldonado, Molina Alcaraz y otros 1991-92). Aunque todavía es pronto para saber si estas comunidades megalíticas pudieron anticiparse a las de Los Millares, es muy posible que, teniendo en cuenta la importancia de su desarrollo y sus propias peculiaridades en un ámbito geográfico plenamente ocupado desde el Neolítico, tengamos que remontar también cronológicamente, los comienzos del Megalitismo del sudeste, sin necesidad de basarnos exclusivamente en la tipología de las tumbas y sus ajuares. De momento, queda claro que en Portugal, y en otras áreas con excavaciones mas recientes y fechas mas precisas, como la Meseta o Cataluña, que, en su origen, el megalitismo se relaciona con el Neolítico, tanto desde un punto de vista cronológico como cultural.

El megalitismo se inició en una fase avanzada del Neolítico, ya dentro del IV milenio, no es un elemento cultural que aparezca de repente ni contemporáneamente a la primera implantación de las formas de vida neolíticas, sino en una fase mas tardía, cuando ya estas se han ido extendiendo prácticamente por todo el 
territorio peninsular. Por otro lado, se siguen construyendo megalitos hasta casi la edad del Bronce. Los hallazgos de la Meseta, muestran que la presencia de campaniforme en alguno de sus ajuares, no se puede explicar simplemente como un fenómeno de intrusismo o reutilización. Excavaciones en Extremadura, Andalucía, la Meseta, la cornisa Cantábrica o Navarra, van ampliando cada vez mas el mapa del megalitismo peninsular, aunque sigue quedando la laguna de la región valenciana, al sur del Ebro y al parecer hasta el Segura-Guadalentín, ya que en estos últimos años se han estudiado una serie de megalitos en el Cerro Negro de Jofre (Lorca) además de los ya conocidos Murviedro, Bagil, Cabezo del Plomo o el Milano, en la provincia de Murcia (Lorca 1994). No es este el momento de tratar el tema de la ausencia de megalitos en Valencia, ya que llevo mas de quince años esperando a que aparezca alguno (Muñoz 1986)

Parece claro que no se puede generalizar, y que cada vez mas, el estudio territorial muestra un evidente polimorfismo, no sólo desde un punto de vista de su estructura constructiva, sino también desde el de su contexto cultural y cronológico. En este aspecto, hay que destacar que desde comienzos de la investigación prehistórica en la Península, en las primeras décadas del siglo XX, se tendió a estudios de tipo regional. En Cataluña, Bosch y su discípulo Pericot destacaron la personalidad de una "cultura pirenaica" (Pericot 1925), en Portugal, en Andalucía, en Extremadura, se excavaron grandes monumentos, pero sin duda fueron los grandes Corpora de los Leisner los que marcaron un nueva línea de investigación que en cierto momento dieron lugar a la aparición de Corpus de megalitos del C.S.I.C. que recogieron las zonas no estudiadas por los Leisner, iniciando una serie que, como las Cartas Arqueológicas, no tuvieron continuidad. De todas formas, las Mesas Redondas como la celebradas en Oporto en 1979, en Madrid en 1984 por la Asociación de Amigos de la Arqueología, el Symposium sobre Arquitectura Megalítica organizado por la Universidad de Barcelona en las Baleares, o la Reunión que sobre El megalitismo en la península Ibérica, organizó en 1987 el Ministerio de Cultura, aparte de los numerosos estudios monográficos (Arribas y Molina 1984; Fábregas Valcarce 1991), dan buena cuenta del interés por las diversas líneas de investigación en torno al megalitismo.

Finalmente, tengo que hacer al menos una referencia al arte megalítico, no sólo porque hay un arte megalítico que algunos han calificado de "necrolátrico", sino también porque no hay duda de que la aportación mas importante al estudio del arte prehistórico peninsular de esta época, se la debemos a Pilar Acosta, también amiga y compañera, y obviamente copartícipe de este Homenaje (Acosta 1968). Teniendo en cuenta que hasta ahora solo he tratado de exponer los fundamentos Neolíticos del megalitismo, voy a hacer lo mismo con su arte, que es un aspecto mas del contexto Neolítico y Calcolítico, sin pretender analizar su manifestaciones recogidas hace unos años (1981) por Elisabeth Shee Twoohig en su magnífico Corpus. Las culturas neolíticas peninsulares, que en su primer momento - neolítico antiguo de cerámicas decoradas - podríamos reducir a dos grupos principales, el de las cerámicas cardiales, y el de las cerámicas incisas-impresas, a partir de su expansión entre las poblaciones indígenas, experimentó una evolución de adaptación a las tradiciones anteriores, dando lugar a manifestaciones nuevas y muy ricas, entre las que destaca el megalitismo con todas sus variantes.

A comienzos del Neolítico, existe en la Península un arte rupestre, el Levantino, arte naturalista, que nos muestra un ambiente mediterráneo con una fauna plenamente adaptada al Holoceno, pero también al hombre que convive con ella. Unas veces observándolos, otras cazándolos y otras compitiendo con otros hombres. Eran cazadores, arqueros y guerreros, que llevaban atuendos que protegían su cuerpo y también adornos en la cabeza y cuerpo, que los personalizaría y serían símbolo de fuerza y de dignidad. Se les representa vivos, dinámicos, en plena actividad con un naturalismo realista, lleno de fuerza, que a su vez nos llena de admiración. Pero la expresión del mundo "levantino" se completa con las escenas en que juega un papel importante la mujer con sus largas faldas y pechos descubiertos. Parecen escenas festivas, con baile y movimiento, que a veces se han interpretado como rituales, por aparecer las mujeres danzando alrededor de un varón muy adornado, interpretado como un brujo. Lo que es evidente es que aunque el centro lo ocupa 
el supuesto brujo, las que dominan la escena son las mujeres que lo cercan o acorralan. El arte levantino, refleja sin duda un arte de cazadores recolectores, que sin duda convivían de cerca con grupos ya neolíticos.

Hay también otro arte rupestre, el llamado esquemático, por la simplicidad expresiva de su trazo, aunque su contenido, lo que expresa, es muy semejante al del arte levantino: cérvidos, équidos, figuras humanas femeninas y masculinas, arqueros (cazadores o guerreros) y también símbolos astrales (soles, estrellas, esteliformes) o representaciones de agua, arboles, que, a mi juicio, no permite generalizar el concepto de simbólico para todo el arte esquemático. Pienso que Pilar Acosta acierta cuando al plantear el origen de este arte esquemático, es partidaria de conjugar los factores autóctonos con los alóctonos y, sobre todo, cuando avisa del peligro de generalizar la cronología de un determinado motivo a áreas geográficamente alejadas. Además, propicia una vía de investigación a partir de representaciones en materiales muebles bien contextualizados (Acosta 1984: 34-40), recogiendo ejemplos de prácticamente todos los temas, que abarcan prácticamente desde el Neolítico antiguo al vaso campaniforme.

Es del mayor interés su observación de que las decoraciones de algunos megalitos del occidente peninsular podrían indicar en esa zona la antigüedad del arte esquemático. Nos encontraríamos con un arte esquemático que, precisamente por aparecer en megalitos antiguos, se remontaría al Neolítico. Aunque hayan pasado ya quince años desde este trabajo pionero, los testimonios de temas esquemáticos en cerámicas neolíticas, sobre todo en Andalucía, van en aumento y, es evidente que, el calificativo de "cerámica simbólica" no se inicia en Los Millares, sino mas bien en tradiciones que se remontan a grupos de cazadores autóctonos, que aparecen en la cerámica desde comienzos del Neolítico.

En cuanto al arte mueble megalítico, si es que podemos llamar así a las ofrendas del ajuar funerario, parece que se sigue admitiendo por los arqueólogos portugueses, que las plaquitas de pizarra con decoración geométrica corresponden al Neolítico del IV milenio, de las antas y cuevas sepulcrales. En cambio, parecen considerar foránea la introducción de los oculados, tanto en las plaquitas como en los ídolos de caliza (Gonçalves 1999). Yo en cambio, comparto la opinión de Pilar Acosta de que el uso de soliformes para la representación de ojos, "en ídolos de tipología variada, muebles o rupestres, e incluso cerámicas, es un aporte eminentemente indígena, de raíz neolítica" (Acosta 1984: 48). En cierto modo, el hallazgo de la Dama de Gavá, en el contexto de los sepulcros de fosa con dataciones del IV milenio, con sus extraños ojos soliformes, viene a reafirmar esta idea (Muñoz 1997 a).

\section{BIBLIOGRAFÍA}

ABERG, N. (1921): La civilisation énéolithique dans la Péninsule Ibérique. Upsala.

ACOSTA MARTÍNEZ, P. (1968): La pintura rupestre esquemática en España. Memorias del Seminario de Prehistoria y Arqueología I. Universidad de Salamanca.

- (1984): "El arte rupestre esquemático ibérico: problemas de cronología preliminares", en J. FORTEA (editor), Scripta Praehistorica Oblata: 31-61. Universidad de Salamanca.

ACOSTA, P. y CRUZ AUÑÓN, R. (1981): "Los enterramientos de las fases iniciales en la Cultura de Almería", Habis 12: 273-360. Sevilla.

ARRIBAS, A. y MOLINA, F. (1984): "Estado actual de la investigación del megalitismo en la Península Ibérica", Scripta Praehistorica, F. Jorda Oblata: 63-112. Salamanca.

BOSCH GIMPERA, P. (1919): Prehistòria catalana. Editora Catalana, Barcelona.

(1932): Etnología de la Península Ibérica. Edit. Alpha, Barcelona.

(1944): El poblamiento antiguo y la formación de los pueblos de España. Universidad de Méjico.

(1965): "La chronologie de l'art rupestre seminaturaliste et eschematique et la culture megalithique portugaise", Separata da Revista da Faculdade de Letras de Lisboa, III série, nº 9, Lisboa. 
CARTAILHAC, E. (1886): Les âges préhistoriques de l'Espagne et de Portugal.

COONEY, G. (1990): "The place of megalithic tombs cemeteries in Ireland", Antiquity 64: 741-753.

FÁBREGAS VALCARCE, R. (1991): Megalitismo del Noroeste de la península Ibérica. Tipología y secuencia de los materiales líticos. UNED, Madrid.

GONÇALVES, V.S.(1989): Megalitismo e metalurgia no Alto Algarve oriental. Uma aproximaçao integrada. 2 Vols. UNIARQ, Lisboa.

(1999): Reguengos de Monsaraz, territórios megalíticos. UNIARQ (Centro de Arqueología da Universidade de Lisboa), Lisboa.

LORCA (1994): Primera arquitectura en piedra: el megalitismo. Museo Arqueológico Municipal. Lorca, abril/mayo

MALDONADO, G.; MOLINA, ALCARAZ, F. y otros (1991-92): "El papel social del megalitismo en el Sureste de la Península Ibérica. Las comunidades megalíticas del pasillo de Tabernas", Cuadernos de Prehistoria de la Universidad de Granada 16-17: 167-190.

MUÑOZ AMILIBIA, A. Mª . (1986): "El Eneolítico en el País Valenciano y Murcia”, en Arqueología en el País Valenciano: panorama y perspectivas: 85-99. Universidad de Alicante.

- (1996): "Reflexiones en torno al megalitismo de Europa occidental", Espacio, Tiempo y Forma, Serie I, Prehistoria y Arqueología, tomo 9: 281-289. UNED, Madrid.

_ (1997): "El mundo indígena del Neolítico al Bronce" Ponencia al XXIV Congreso Nacional de Arqueología: 72-83. Cartagena.

(1997 a): "La cultura de los sepulcros de fosa: una sociedad neolítica". Espacio, Tiempo y forma, Serie Prehistoria y Arqueología, tomo 10: 265-278. UNED, Madrid.

MOLINA, F. (1991): "Proyecto Millares (Los inicios de la metalurgia y el desarrollo de las comunidades del Sudeste de la Península Ibérica durante la edad del Cobre)", Anuario Arqueologico de Andalucía, 1989 II: 211-213. Sevilla.

PERICOT, L. (1925): La civilización megalítica catalana y la cultura Pirenaica. Barcelona.

RENFREW, C. (1973): The radiocarbon revolution and Prehistoric Europe. Penguin Books, Suffolk.

SAVORY, H. (1968): Spain and Portugal. The Prehistory of the Iberian Peninsula. Thames and Hudson, Londres.

ZILHAO, J. (1992): La Grutta do Caldeirao. O Neolitico Antigo. Instituto Português do Patrimonio Arquitectónico e Arqueologico, Trabalhos de Arqueología 6, Lisboa.

(1995): "Primeiras Dataçoes absolutas para os Niveis Neolíticos das Grutas do Caldeirâo e da Feteira. Suas implicaçôes para a cronologia da pré-história do Sul de Portugal”, en M. KUNST (Coord:) Origens, Estruturas e Relaçoes das Culturas Calcolíticas da Península Ibérica. I Jornadas Arqueológicas de Torres Vedras (3-5 abri 1987): 113-122. Instituto Português do Patrimonio Arquitectónicoe Arqueológico, Lisboa. 